\title{
Significant improvement in postoperative and 1-year mortality after colorectal cancer surgery in recent years
}

Citation for published version (APA):

Ketelaers, S. H. J., Orsini, R. G., Burger, J. W. A., Nieuwenhuijzen, G. A. P., \& Rutten, H. J. T. (2019). Significant improvement in postoperative and 1-year mortality after colorectal cancer surgery in recent years. European Journal of Surgical Oncology, 45(11), 2052-2058.

https://doi.org/10.1016/j.ejso.2019.06.017

Document status and date:

Published: 01/11/2019

DOI:

10.1016/j.ejso.2019.06.017

Document Version:

Publisher's PDF, also known as Version of record

\section{Document license:}

Taverne

Please check the document version of this publication:

- A submitted manuscript is the version of the article upon submission and before peer-review. There can be important differences between the submitted version and the official published version of record.

People interested in the research are advised to contact the author for the final version of the publication, or visit the DOI to the publisher's website.

- The final author version and the galley proof are versions of the publication after peer review.

- The final published version features the final layout of the paper including the volume, issue and page numbers.

Link to publication

\footnotetext{
General rights rights.

- You may freely distribute the URL identifying the publication in the public portal. please follow below link for the End User Agreement:

www.umlib.nl/taverne-license

Take down policy

If you believe that this document breaches copyright please contact us at:

repository@maastrichtuniversity.nl

providing details and we will investigate your claim.
}

Copyright and moral rights for the publications made accessible in the public portal are retained by the authors and/or other copyright owners and it is a condition of accessing publications that users recognise and abide by the legal requirements associated with these

- Users may download and print one copy of any publication from the public portal for the purpose of private study or research.

- You may not further distribute the material or use it for any profit-making activity or commercial gain

If the publication is distributed under the terms of Article $25 \mathrm{fa}$ of the Dutch Copyright Act, indicated by the "Taverne" license above, 


\title{
Significant improvement in postoperative and 1-year mortality after colorectal cancer surgery in recent years
}

\author{
S.H.J. Ketelaers ${ }^{\text {a }}$, R.G. Orsini a , J.W.A. Burger ${ }^{\text {a }}$, G.A.P. Nieuwenhuijzen ${ }^{\text {a }}$, H.J.T. Rutten ${ }^{\text {a, b, * }}$ \\ ${ }^{a}$ Department of Surgery, Catharina Hospital Eindhoven, the Netherlands \\ b GROW: School of Oncology and Developmental Biology, University of Maastricht, Maastricht, the Netherlands
}

\section{A R T I C L E I N F O}

\section{Article history:}

Received 8 May 2019

Received in revised form

22 May 2019

Accepted 12 June 2019

Available online 13 June 2019

\section{Keywords:}

Colon cancer

Rectal cancer

Curative surgery

Senior patients

Survival

Morbidity

\begin{abstract}
A B S T R A C T
Background: In earlier studies an association between older patients and higher morbidity and mortality after colorectal surgery is shown, especially in the first postoperative year. We conducted this study to investigate if there is improvement in postoperative morbidity and mortality in senior CRC patients over time.

Materials and methods: All patients, except those with distant metastasis, who received curative CRC surgery between 2006 and 2017 in the Catharina Hospital (Eindhoven, the Netherlands) were selected retrospectively. Differences in mortality and relative survival between different age groups ( $<75$ and $\geq 75$ years), period of surgery (2006-2012 and 2013-2017) and type of tumor (colon and rectum) were investigated.

Results: In total 2018 patients, of whom $57.4 \%$ is male, were selected $(\mathrm{n}=1037$ colon and $\mathrm{n}=981$ rectum). 615 (30.5\%) patients were $\geq 75$ years old. For electively treated CRC patients aged $\geq 75$ years 30 and 90 -day mortality improved from $5.8 \%$ to $1.2 \%(\mathrm{p}=0.004)$ and $9.1 \%$ to $4.6 \%(\mathrm{p}=0.043)$ respectively, in favour of the latest time period. Relative one-year survival rates of all electively treated CRC patients were not significantly different between younger and older patients in the latest time period $(95.5 \% \mathrm{vs}$. 94.3\%, $\mathrm{p}=$ n.s.)

Conclusions: This study shows significant improvement in postoperative morbidity and mortality over time for both age and treatment groups. Relative survival rates improved especially for older patients and no significant differences were seen between both age groups. Senior CRC patients should not be withheld curative treatment based on age or comorbidities alone.
\end{abstract}

๑) 2019 Elsevier Ltd, BASO The Association for Cancer Surgery, and the European Society of Surgical Oncology. All rights reserved.

\section{Introduction}

The incidence of colorectal cancer (CRC) increases with age. As worldwide age is increasing, more and more older patients are diagnosed with CRC [1]. With more senior patients affected by CRC, challenges originate in treatment choices. These patients are a heterogeneous group of patients with variations in fragility and comorbidities, and with inconsistencies between physical and chronological age [2]. They are at risk for complications with increased morbidity and post-operative mortality and if complications occur, they have more devastating consequences [3-5].

\footnotetext{
* Corresponding author. Department of Surgery, Catharina Hospital, PO Box 1350, 5602 ZA, Eindhoven, the Netherlands.
}

E-mail address: harm.rutten@catharinaziekenhuis.nl (H.J.T. Rutten).
Furthermore, the percentage of seniors who receive surgery decreases with older ages [6]. In daily practice these findings could lead to withholding potentially curative treatment in the older population with an increased risk for undertreatment $[7,8]$.

There is increasing evidence that older patients who are fit enough for surgery have the same benefit from potentially curative treatment as younger patients do [9,10]. They are able to withstand the surgical stressor better than commonly believed $[9,10]$. However, the risk of mortality in seniors during the first post-operative year is $20-23 \%$ [11]. If they survive the first year, their prognosis is equal to younger counterparts if they survive the first postoperative year [11].

In senior patients, one of the most important determinating factors in decision making is frailty. This is important because this condition, defined as a state of limited reserve to undergo physical stress, is a known risk factor for postoperative complications in 
colorectal cancer surgery [12]. In case of increased frailty or limited functional reserve, a prehabilitation program could be beneficial for senior patients to improve their condition prior to surgery [13]. However, until now evidence on the effect of prehabilitation on post-operative outcome is varying and inconclusive $[13,14]$.

Improvement in earlier diagnosis, better staging, less invasive surgical techniques, pre- and postoperative care and centralization of complex cases have contributed to an improved outcome in the older patient [1]. Despite all these improvements, studies still report significant differences in 30-day and one-year mortality between older and younger CRC patients [11]. However, there is a possibility that these differences are changing over time.

The primary aim of this study is to investigate whether or not any improvement in short-term morbidity and mortality has occurred in senior CRC patients over the years treated in a highvolume center for complex CRC cases. The secondary aim is to compare these morbidity and mortality rates between younger and older CRC patients.

\section{Materials and methods}

\section{Patients and treatment}

The Catharina Hospital (Eindhoven, the Netherlands) is a specialized and high-volume center for treatment of CRC and is a referral center for locally advanced and recurrent colorectal cancer. For this study, all patients receiving curative surgery for primary non-recurrent colorectal cancer between 2006 and 2017 were selected. Almost all patients, except those undergoing emergency procedures, were adequately staged locally and systemically with histologically proven CRC and a pretreatment CT or MRI scan. Depending on location of the tumor and cancer stage, patients received neo-adjuvant and/or adjuvant treatment with (chemo) radiation, according to the Dutch National Guidelines for colorectal cancer [15]. Type of surgery (e.g. laparoscopic and open surgery) was used depending on the type and stage of the tumor and the preference of the surgeon. Patients with peritonitis carcinomatosis and distant metastasis at time of presentation were excluded in this study. All patients were assessed independently by a surgeon and an anesthesiologist to determine whether or not they were regarded fit for surgery. Besides the standard medical history regarding previous morbidities and co-existing morbidities, nutritional assessment, drug use and a somatic and psychogeriatric screening, also the support system at home and the requirements after surgery to return home were evaluated. If needed, other disciplines were involved.

\section{Clinical data and follow-up}

Clinical and demographic data were extracted retrospectively from medical records. Complications were scored using the Clavien-Dindo classification of surgical complications [16,17]. Follow-up data was extracted from medical records or by contacting the patient, the referring hospital or patients' general practitioner by telephone. Time to follow-up was calculated as the interval from the day of surgery to death or to the date of last contact. Minimum follow-up time of the surviving patients was at least one year. The vital status of all patients was assessed through linkage with Municipal Administrative Databases, which register all deceased and emigrated persons in the Netherlands. If a patient had died during follow-up the date and cause of death were noted.

\section{Statistical analyses}

Statistical analyses were performed using SPSS Statistics 25.0 software (IBM, Endicott, New York, USA). Patients were divided in two consecutive periods based on year of surgery: 2006-2012 and 2013-2017. All analyses were performed separately for both colon and rectal cancer. Survival analyses were performed only for CRC patients treated with elective surgery. Comparisons within these groups were based on age ( $<75$ and $\geq 75$ years). All survival analyses were also performed for patients $<80$ and $\geq 80$ years, and shown in supplementary data. Intergroup comparisons were analyzed using chi-square tests or independent t-tests when appropriate. A p-value of $<0.05$ was considered statistically significant. Survival rates were analyzed for colon and rectal cancer separately and were stratified by age group using the Kaplan-Meier method. To calculate disease-specific survival we used relative survival rates, which was calculated as the absolute survival amongst CRC patients divided by the expected survival for the general population with the same sex and age structure.

\section{Results}

In total 2018 consecutive CRC patients were included. Of the 1037 colon cancer patients, $432(41.7 \%)$ were $\geq 75$ years old and of the 981 rectal cancer patients, 183 (18.7\%) were $\geq 75$ years old. Median follow-up time for colon cancer patients was 3.4 years and for rectal cancer patients 4.2 years. Senior ( $\geq 75$ years) CRC patients had significantly more comorbidities compared to younger patients. Further clinical and demographic characteristics for both colon and rectal cancer patients are presented separately in Tables 1 and 2 , respectively.

\section{Postoperative morbidity and mortality}

Senior colon cancer patients had significantly more pulmonary, cardiac and neurological complications compared to younger patients. Clavien-Dindo grade III complications were observed in $6.0 \%$ of the older and in $9.4 \%$ of the younger patients $(p=0.046)$. Clavien-Dindo grade IV complications occurred in $1.9 \%$ of the older and in $2.6 \%$ of the younger patients ( $\mathrm{p}=\mathrm{n}$.s.). Post-operative mortality during admission was observed in 25 (5.8\%) of the older and $11(1.8 \%)$ of the younger patients $(\mathrm{p}=0.001)$.

Senior rectal cancer patients also had significantly more pulmonary, cardiac and neurological complications. The incidence of other complications was similar compared to younger patients. Of the older patients, $11.5 \%$ and $4.9 \%$ of patients developed grade III or IV complications in comparison to $11.2 \%$ and $3.1 \%$ in younger patients, respectively $(\mathrm{p}=$ n.s.). Post-operative mortality during admission occurred in $8(4.4 \%)$ older and in $9(1.1 \%)$ younger patients $(\mathrm{p}=0.002)$. A detailed description of the complications in both groups is presented in Table 3 .

\section{Development of post-operative morbidity and mortality over time}

In the period $2006-2012,9.7 \%$ and $2.8 \%$ of the older and $12.8 \%$ and $3.5 \%$ of the younger CRC patients developed grade III or grade IV complications, respectively. Post-operative mortality during admission was observed in $8.8 \%$ of the older compared to $1.3 \%$ of the younger patients $(\mathrm{p}<0.001)$.

In the period 2013-2017, no significant differences in complications or mortality between older and younger patients were seen. Grade III or IV complications occurred in $5.4 \%$ and $2.7 \%$ of the older and $7.7 \%$ and $2.3 \%$ of the younger patients, respectively. Postoperative mortality during admission in this period occurred in $1.7 \%$ of the older and $1.5 \%$ of the younger patients $(\mathrm{p}=0.842)$. 
Table 1

Demographic and clinical characteristics of all 1037 colon cancer patients stratified by age group and period of treatment.

\begin{tabular}{|c|c|c|c|c|c|c|}
\hline & \multicolumn{6}{|l|}{ Colon $\mathbf{n}=1037$} \\
\hline & \multicolumn{3}{|l|}{$<75$ years } & \multicolumn{3}{|l|}{$\geq 75$ years } \\
\hline & $2006-2012 n=287$ & $2013-2017 n=318$ & p-value & $2006-2012 n=205$ & $2013-2017 n=227$ & p-value \\
\hline & $n(\%)$ & $n(\%)$ & & $n(\%)$ & $n(\%)$ & \\
\hline Mean age in years at time of surgery (range) & $64.4(24.4-74.9)$ & $65.4(30.3-74.9)$ & 0.149 & $81.6(75.1-96.1)$ & $80.6(75.0-95.2)$ & 0.017 \\
\hline Median follow-up in years $( \pm S D)$ & $7.1(3.1)$ & $2.4(1.4)$ & & $4.9(3.4)$ & $2.2(1.4)$ & \\
\hline Male & $152(53.0)$ & $181(56.9)$ & 0.329 & $102(49.8)$ & $111(48.9)$ & 0.859 \\
\hline Comorbidity & & & 0.083 & & & 0.008 \\
\hline None & $92(32.1)$ & $120(37.7)$ & & $31(15.1)$ & $65(28.6)$ & \\
\hline 1 comorbidity & $54(18.8)$ & $73(23.0)$ & & $34(16.6)$ & $35(15.4)$ & \\
\hline 2 comorbidities & $47(16.4)$ & $48(15.1)$ & & $38(18.5)$ & $38(16.7)$ & \\
\hline$\geq 3$ comorbidities & $94(32.8)$ & $77(24.2)$ & & $102(49.8)$ & $89(39.2)$ & \\
\hline ASA classification & & & 0.330 & & & 0.417 \\
\hline I-II & $218(76.0)$ & $254(79.9)$ & & $100(48.8)$ & $123(54.2)$ & \\
\hline III & $67(23.3)$ & $60(18.9)$ & & $94(45.9)$ & $96(42.3)$ & \\
\hline IV & $2(0.7)$ & $4(1.3)$ & & $11(5.4)$ & $8(3.5)$ & \\
\hline Type of surgery & & & 0.137 & & & 0.165 \\
\hline Right hemicolectomy & $125(43.6)$ & $117(36.8)$ & & $106(51.7)$ & $122(53.7)$ & \\
\hline Transversum colectomy & $5(1.7)$ & $4(1.3)$ & & $7(3.4)$ & $2(0.9)$ & \\
\hline Left hemicolectomy & $36(12.5)$ & $62(19.5)$ & & $22(10.7)$ & $36(15.9)$ & \\
\hline Sigmoid & $109(38.0)$ & $125(39.3)$ & & $68(33.2)$ & $64(28.2)$ & \\
\hline (Sub)total colectomy & $12(4.2)$ & $10(3.1)$ & & $2(1.0)$ & $3(1.3)$ & \\
\hline Initial type of intervention & & & $<0.001$ & & & $<0.001$ \\
\hline Open surgery & $184(64.1)$ & $105(33.0)$ & & $158(77.1)$ & $86(37.9)$ & \\
\hline Laparoscopic & $103(35.9)$ & $213(67.0)$ & & $47(22.9)$ & $141(62.1)$ & \\
\hline Stoma during surgery & & & $<0.001$ & & & $<0.001$ \\
\hline Yes & $29(10.1)$ & $40(12.6)$ & & $29(14.1)$ & $30(13.2)$ & \\
\hline No & $236(82.2)$ & $276(86.8)$ & & $159(77.6)$ & $197(86.8)$ & \\
\hline Missing & $22(7.7)$ & $2(0.6)$ & & $17(8.3)$ & - & \\
\hline Emergency surgery & $32(11.1)$ & $35(11.0)$ & 0.955 & 40 (19.5) & $37(16.3)$ & 0.384 \\
\hline Extended (multivisceral) resection & $34(11.8)$ & $31(9.7)$ & 0.001 & $23(11.2)$ & $21(9.3)$ & 0.001 \\
\hline Missing & $18(6.3)$ & $51(16.0)$ & & $7(3.4)$ & $30(13.2)$ & \\
\hline Mean hospital stay in days $( \pm S D)$ & $9.7(8.9)$ & $9.0(10.6)$ & 0.381 & $12.6(10.8)$ & $9.6(7.2)$ & 0.001 \\
\hline Mean ICU stay in days $( \pm \mathrm{SD})$ & $0.7(2.1)$ & $1.1(5.9)$ & 0.466 & $2.2(3.5)$ & $1.0(2.8)$ & 0.020 \\
\hline Pathological T-stage & & & 0.023 & & & 0.915 \\
\hline T0-T2 & $75(26.1)$ & $110(34.6)$ & & $52(25.4)$ & $60(26.4)$ & \\
\hline T3 & $156(54.4)$ & $145(45.6)$ & & $117(57.1)$ & $125(55.1)$ & \\
\hline $\mathrm{T} 4$ & $56(19.5)$ & $59(18.6)$ & & $36(17.6)$ & $42(18.5)$ & \\
\hline $\mathrm{Tx}$ & - & $4(1.3)$ & & & & \\
\hline Pathological N-stage & & & 0.428 & & & 0.572 \\
\hline NO & $178(62.0)$ & $191(60.1)$ & & $146(71.2)$ & $153(67.4)$ & \\
\hline N1 & $62(21.6)$ & $82(25.8)$ & & $36(17.6)$ & $49(21.6)$ & \\
\hline N2 & $47(16.4)$ & $45(14.2)$ & & $23(11.2)$ & $25(11.0)$ & \\
\hline Primary anastomosis & $272(94.8)$ & $299(94.0)$ & 0.690 & $183(89.3)$ & $207(91.2)$ & 0.501 \\
\hline Radical resection (R0) & $287(100.0)$ & 317 (99.7) & 0.342 & $205(100.0)$ & $227(100.0)$ & NA \\
\hline
\end{tabular}

\section{Overall and relative survival analysis}

Comparing the 2006-2012 and 2013-2017 period, the overall 30- and 90-day mortality for senior CRC patients decreased from $5.8 \%$ to $1.2 \%(\mathrm{p}=0.004)$ and from $9.1 \%$ to $4.6 \%(\mathrm{p}=0.043)$, respectively. For patients $<75$ years no differences in 30- and 90-day survival rates were seen between both time periods (Fig. 1). In contrast to the period 2006-2012, the most recent time period showed there were no significant differences in the 30- and 90-day mortality rate between both age groups for both colon and rectal cancer patients. The 30-day and 90-day mortality rate in this period was $1.1 \%$ and $4.2 \%$ for senior colon and $1.4 \%$ and $5.8 \%$ in senior rectal cancer patients, respectively. A more detailed description of the overall survival rates for all groups is presented in Table 4.

For all CRC patients, absolute one-year survival was $95.3 \%$ and 85.5\% for younger and older patients in the 2006-2012 period compared to $94.9 \%$ and $89.2 \%$ in the $2013-2017$ period, respectively $(\mathrm{p}=0.002)$. In the most recent time period, no significant differences were found in overall one-year mortality between younger and older colon cancer patients $(90.5 \%$ vs. 95.1\%, respectively $\mathrm{p}=0.055$ ). In rectal cancer patients there were still significant differences between older and younger patients in overall one-year mortality for the same period ( $85.5 \%$ vs. $94.7 \%, \mathrm{p}=0.006$ ).

The relative one-year survival for senior CRC patients improved from $88.4 \%$ in the $2006-2012$ period to $94.3 \%$ in the latest time period and was not significantly different compared to younger patients for this latest time period. Improvement of the relative survival was observed for both colon and rectal cancer patients. Also in senior patients who underwent emergency surgery for CRC, similar relative one-year survival rates as their younger counterparts were seen in the period 2013-2017. The relative one-year survival rates are presented in Table 5 .

\section{Discussion}

Potentially curative treatment for colorectal cancer is accompanied by acceptable morbidity and low mortality rates for all patients regardless of age [18-21]. However, earlier studies on this topic showed that morbidity in senior patients is most often higher than in their younger counterparts, and the risk for mortality is increased if a complication occurs [3,4]. Our cohort of consecutive CRC patients shows a major decrease in 90-day and one-year mortality in the older population. For the period 2006-2012, 9.1\% patients aged $\geq 75$ years died in the first 90 days compared to $4.6 \%$ 
Table 2

Demographic and clinical characteristics of all 981 rectal cancer patients stratified by age group and period of treatment.

\begin{tabular}{|c|c|c|c|c|c|c|}
\hline & \multicolumn{6}{|l|}{ Rectum n $=981$} \\
\hline & \multicolumn{3}{|l|}{$<75$ years } & \multicolumn{3}{|l|}{$\geq 75$ years } \\
\hline & $2006-2012 n=454$ & $2013-2017 n=344$ & p-value & $2006-2012 n=113$ & $2013-2017 n=70$ & p-value \\
\hline & $n(\%)$ & $n(\%)$ & & $n(\%)$ & $n(\%)$ & \\
\hline Mean age in years at time of surgery (range) & $61.8(27.0-74.9)$ & $62.2(28.8-74.9)$ & 0.519 & $79.3(75.0-88.6)$ & $79.7(75.0-90.6)$ & 0.531 \\
\hline Median follow-up in years $( \pm S D)$ & $7.1(3.2)$ & $2.7(1.4)$ & & $4.5(3.2)$ & $1.8(1.4)$ & \\
\hline Male & $277(61.0)$ & $223(64.8)$ & 0.270 & $68(60.2)$ & $45(64.3)$ & 0.578 \\
\hline Comorbidity & & & 0.117 & & & 0.024 \\
\hline None & $180(39.6)$ & $139(40.4)$ & & $18(15.9)$ & $25(35.7)$ & \\
\hline 1 comorbidity & $107(23.6)$ & $70(20.3)$ & & $23(20.4)$ & $10(14.3)$ & \\
\hline 2 comorbidities & $90(19.8)$ & $56(16.3)$ & & $22(19.5)$ & $11(15.7)$ & \\
\hline$\geq 3$ comorbidities & $77(17.0)$ & $79(23.0)$ & & $50(44.2)$ & $24(34.3)$ & \\
\hline ASA classification & & & 0.686 & & & 0.253 \\
\hline I-II & $392(86.3)$ & $292(85.2)$ & & $68(60.2)$ & $48(68.6)$ & \\
\hline III & $61(13.4)$ & $49(14.2)$ & & $42(37.2)$ & $22(31.4)$ & \\
\hline IV & $1(0.2)$ & $1(0.3)$ & & $3(2.7)$ & - & \\
\hline Neo-adjuvant treatment & & & $<0.001$ & & & 0.659 \\
\hline None & $51(11.2)$ & $59(17.2)$ & & $33(29.2)$ & $17(24.3)$ & \\
\hline Short course radiotherapy ( $5 \times 5 \mathrm{~Gy})$ & $85(18.7)$ & $47(13.7)$ & & $32(28.3)$ & $24(34.3)$ & \\
\hline Chemoradiation & $298(65.6)$ & $237(68.9)$ & & $44(38.9)$ & $28(40.0)$ & \\
\hline Long course radiotherapy & $20(4.4)$ & $1(0.3)$ & & $4(3.5)$ & $1(1.4)$ & \\
\hline Type of surgery & & & 0.489 & & & 0.263 \\
\hline Low anterior resection & $270(59.5)$ & $212(61.6)$ & & $56(49.6)$ & $43(61.4)$ & \\
\hline Abdominoperineal resection & $171(37.7)$ & $121(35.2)$ & & $45(39.8)$ & $24(34.3)$ & \\
\hline (Sub)total resection & $2(0.4)$ & - & & $2(1.8)$ & - & \\
\hline TEM & $11(2.4)$ & $11(3.2)$ & & $10(8.8)$ & $3(4.3)$ & \\
\hline Initial type of intervention & & & $<0.001$ & & & $<0.001$ \\
\hline Open surgery & $432(95.2)$ & $263(76.5)$ & & $99(87.6)$ & $51(72.9)$ & \\
\hline Laparoscopic & $11(2.4)$ & $70(20.3)$ & & $4(3.5)$ & $16(22.9)$ & \\
\hline Ostomy during surgery & & & 0.001 & & & 0.628 \\
\hline Yes & $379(83.5)$ & $270(78.5)$ & & $90(79.6)$ & $55(78.6)$ & \\
\hline No & $55(12.1)$ & $69(20.1)$ & & $17(15.0)$ & $13(18.6)$ & \\
\hline Missing & $20(4.4)$ & $5(1.5)$ & & $6(5.3)$ & $2(2.9)$ & \\
\hline Emergency surgery & $6(1.3)$ & $4(1.2)$ & 0.842 & $3(2.7)$ & $1(1.4)$ & 0.581 \\
\hline Clinical T-stadium & & & 0.990 & & & 0.633 \\
\hline $\mathrm{T} 1-\mathrm{T} 2$ & $67(14.8)$ & $50(14.5)$ & & $23(20.4)$ & $16(22.9)$ & \\
\hline T3 & $183(40.3)$ & $136(39.5)$ & & $48(42.5)$ & $24(34.3)$ & \\
\hline $\mathrm{T} 4$ & $203(44.7)$ & $157(45.6)$ & & $39(34.5)$ & $29(41.4)$ & \\
\hline $\mathrm{Tx}$ & $1(0.2)$ & $1(0.3)$ & & $3(2.7)$ & $1(1.4)$ & \\
\hline Clinical N-stadium & & & $<0.001$ & & & $<0.001$ \\
\hline No & $164(36.1)$ & $92(26.7)$ & & $54(47.8)$ & $29(41.4)$ & \\
\hline N1 & $88(19.4)$ & $102(29.7)$ & & $20(17.7)$ & $22(31.4)$ & \\
\hline $\mathrm{N} 2$ & $102(22.5)$ & $141(41.0)$ & & $10(8.8)$ & $19(27.1)$ & \\
\hline $\mathrm{Nx}$ & $19(4.2)$ & $8(2.3)$ & & $4(3.5)$ & - & \\
\hline Missing & $81(17.8)$ & $1(0.3)$ & & $25(22.1)$ & - & \\
\hline Extended (multivisceral) resection & $145(29.7)$ & $121(35.2)$ & 0.006 & $34(30.1)$ & $29(41.4)$ & 0.098 \\
\hline Missing & $36(7.9)$ & $10(2.9)$ & & $11(9.7)$ & $2(2.9)$ & \\
\hline Mean admission time in days $( \pm \mathrm{SD})$ & $11.6(10.7)$ & $9.4(6.7)$ & 0.001 & $14.5(12.8)$ & $12.7(10.6)$ & 0.329 \\
\hline Mean admission time on ICU in days $( \pm \mathrm{SD})$ & $1.7(7.5)$ & $0.9(1.8)$ & 0.129 & $1.9(3.3)$ & $2.1(3.6)$ & 0.798 \\
\hline Primary anastomosis & $264(58.1)$ & $200(58.1)$ & 0.684 & $41(36.3)$ & $32(45.7)$ & 0.205 \\
\hline Radical resection ( $\mathrm{R} 0)$ & $446(98.2)$ & $340(98.8)$ & 0.491 & $108(95.6)$ & $69(98.6)$ & 0.269 \\
\hline
\end{tabular}

Table 3

Complications in both colon and rectal cancer patients, stratified by age groups.

\begin{tabular}{|c|c|c|c|c|c|c|}
\hline & \multicolumn{3}{|l|}{ Colon $n=1037$} & \multicolumn{3}{|l|}{ Rectum n $=981$} \\
\hline & $<75$ years $n=605$ & $\geq 75$ years $n=432$ & p-value & $<75$ years $n=798$ & $\geq 75$ years $n=183$ & p-value \\
\hline & $n(\%)$ & $n(\%)$ & & $n(\%)$ & $n(\%)$ & \\
\hline Pulmonary & $44(7.3)$ & $59(13.7)$ & 0.001 & $62(7.8)$ & $25(13.7)$ & 0.011 \\
\hline Cardiac & $20(3.3)$ & $47(10.9)$ & $<0.001$ & $35(4.4)$ & $18(9.8)$ & 0.003 \\
\hline Infectious & $52(8.6)$ & $30(6.9)$ & 0.332 & $92(11.5)$ & $27(14.8)$ & 0.228 \\
\hline Neurological & $13(2.1)$ & $37(8.6)$ & $<0.001$ & $18(2.3)$ & $18(9.8)$ & $<0.001$ \\
\hline Thrombosis & $7(1.2)$ & $3(0.7)$ & 0.452 & $13(1.6)$ & $1(0.5)$ & 0.265 \\
\hline Clavien-Dindo grade & & & $<0.001$ & & & $<0.001$ \\
\hline None & $385(63.6)$ & $248(57.4)$ & & 398 (49.9) & $65(35.5)$ & \\
\hline Grade I-II & $136(22.5)$ & $125(28.9)$ & & $277(34.7)$ & $80(43.7)$ & \\
\hline Grade IIIa & $13(2.1)$ & $9(2.1)$ & & $29(3.6)$ & $2(1.1)$ & \\
\hline Grade IIIb & $44(7.3)$ & $17(3.9)$ & & $60(7.5)$ & $19(10.4)$ & \\
\hline Grade IV & $16(2.6)$ & $8(1.9)$ & & $25(3.1)$ & $9(4.9)$ & \\
\hline Grade V & $11(1.8)$ & $25(5.8)$ & & $9(1.1)$ & $8(4.4)$ & \\
\hline
\end{tabular}




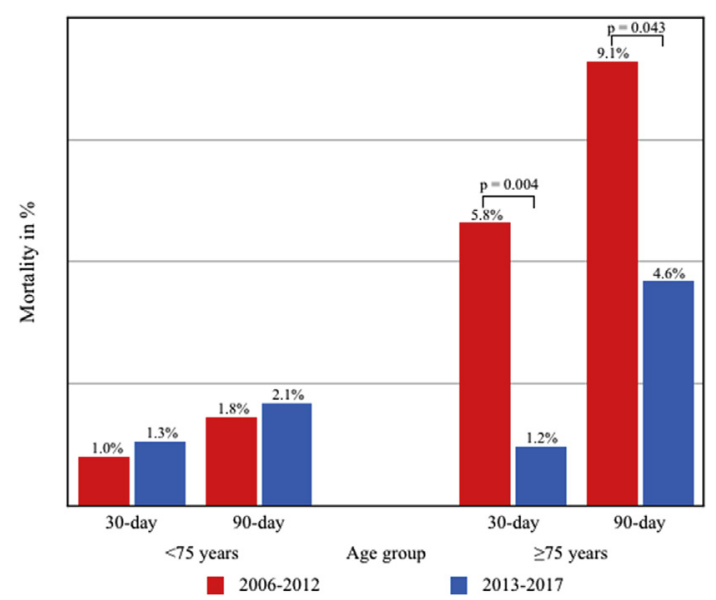

Fig. 1. Improvement of short-term mortality for elderly colorectal cancer patients over the years.

in the most recent period. After correcting absolute mortality for age-related background mortality (relative survival), one-year survival rates were almost equal for younger and older patients: $95.5 \%$ and $94.3 \%$, respectively. Although overall mortality in senior patients is higher, the impact of current CRC treatment on mortality is equal between both patient groups. We believe that improvement in peri-operative and post-operative care have contributed to this positive effect. Since senior patients had significantly more comorbidities than younger patients, the differences in overall mortality between ages are most probably accountable on other diseases which affect these patients.

Older studies focusing on outcome in the older CRC population report 30-day mortality rates up to $7 \%$ in patients aged 75 years or older and one-year mortality rates of 19-26\% [18,22-25]. However, this study, showed a 30 -day mortality rate of $1.1 \%$ in senior colon and $1.4 \%$ in senior rectal cancer patients for the most recent period. In a population based study from The Netherlands, including patients surgically treated for CRC between 2009 and 2013, an improvement was observed in 30-day and one-year mortality for patients $\geq 75$ years old over the years [26]. They reported mortality rates in patients $\geq 75$ years that were slightly higher compared to our rates, $2.9-6.2 \%$ and $11.7-15.0 \%$, respectively for one-month and one-year mortality [26]. Another recent population-based cohort study across four North European countries also showed somewhat higher 30-day, 90-day and overall one-year mortality rates for octogenarian colon and rectal cancer patients [27]. For octogenarian colon cancer patients they reported 30-day and one-year mortality rates of $5.5-11.4 \%$ and $17.1-23.6 \%$, respectively [27]. For the octogenarian rectal cancer patients these rates were $4.7-7.5 \%$ and $13.6-22.1 \%$, respectively [27]. This study also showed that short-term mortality improved over the years, which varied substantially between different countries [27]. These rates were even slightly higher than we found for patients $\geq 80$ years old in our cohort (shown as supplementary data). A small single institution study of 85 patients from the United Kingdom including CRC patients showed a 30-day mortality rate for patients $\geq 75$ years of $6.5 \%$, which was almost equal to that of younger patients [23]. Others studies focusing on survival rates over the years have also shown improved survival rates in senior CRC patients [1,22,28,29].

The reported survival rates in this study are promising, particularly as a significant proportion of the senior rectal cancer patients have locally advanced cases. These patients require intensive treatment regimens with neo-adjuvant treatment and in about one third of the cases multivisceral resections. Possible explanations for improvement in short-term survival rates in senior colon cancer patients are probably due to increasing use of minimal invasive techniques and peri-operative measures. However in rectal cancer patients there is not a clear surgical explanation as most patients

Table 4

Absolute survival rates of both colon and rectal cancer patients with elective surgery, stratified by age groups.

\begin{tabular}{|c|c|c|c|c|}
\hline & \multicolumn{4}{|l|}{ Colon $n=893$} \\
\hline & \multicolumn{2}{|l|}{$<75$ years } & \multicolumn{2}{|l|}{$\geq 75$ years } \\
\hline & $2006-2012 n=255$ & $2013-2017 n=283$ & $2006-2012 n=165$ & $2013-2017 n=190$ \\
\hline 1-month & 0.98 & 0.99 & 0.94 & 0.99 \\
\hline 3-month & 0.97 & 0.98 & 0.90 & 0.94 \\
\hline 6-month & 0.96 & 0.97 & 0.88 & 0.90 \\
\hline \multirow[t]{2}{*}{1 -year } & 0.95 & 0.95 & 0.86 & 0.85 \\
\hline & $\begin{array}{l}\text { Rectum } n=967 \\
<75 \text { years } \\
2006-2012 n=448\end{array}$ & $2013-2017 n=340$ & $\begin{array}{l}\geq 75 \text { years } \\
2006-2012 n=110\end{array}$ & $2013-2017 n=69$ \\
\hline 1-month & 0.99 & 0.99 & 0.94 & 0.99 \\
\hline 3-month & 0.98 & 0.98 & 0.92 & 0.94 \\
\hline 6-month & 0.98 & 0.97 & 0.90 & 0.90 \\
\hline 1-year & 0.95 & 0.95 & 0.85 & 0.85 \\
\hline
\end{tabular}

Table 5

Relative one-year survival rates, stratified by age and period of surgery.

\begin{tabular}{|c|c|c|c|c|c|c|}
\hline & \multicolumn{6}{|c|}{ Relative one-year survival } \\
\hline & \multicolumn{3}{|l|}{ 2006-2012 } & \multicolumn{3}{|l|}{ 2013-2017 } \\
\hline & $<75$ years & $\geq 75$ years & p-value & $<75$ years & $\geq 75$ years & p-value \\
\hline & $\%$ & $\%$ & & $\%$ & $\%$ & \\
\hline All CRC patients & $96.5 \%$ & $88.4 \%$ & $<0.001$ & $95.5 \%$ & $94.3 \%$ & 0.429 \\
\hline Colon & $96.5 \%$ & $87.3 \%$ & $<0.001$ & $95.3 \%$ & $94.7 \%$ & 0.429 \\
\hline Rectum & $96.3 \%$ & $89.4 \%$ & 0.003 & $95.3 \%$ & $91.2 \%$ & 0.176 \\
\hline Emergency surgery & $100 \%$ & $69.8 \%$ & $<0.001$ & $87.2 \%$ & $92.1 \%$ & 0.479 \\
\hline
\end{tabular}


are treated with open surgery due to the locally advanced nature of most cases. However, increased expertise in these cases with improved perioperative care and awareness of complications will probably attribute to these improved outcomes. Another possible explanation for better short-term outcomes is the introduction and standardization of the Enhanced Recovery After Surgery (ERAS) program, that showed promising results in the postoperative phase [27].

All patients with CRC need to be adequately staged and performance status needs to be assessed. It is known that frailty is a relevant risk factor for postoperative complications, longer hospital stay, readmission rates and lower long-term survival [30,31]. In order to prevent adverse outcomes in older CRC patients it is important to recognize frailty to determine the most appropriate therapeutic regimen. It is still a discussion how frailty should be adequately identified in the individual patient, as no specific tool is able to identify all heterogeneous aspects of frailty [8,32]. Montroni et al. recommend focusing on main predictors as functional and nutritional status and comorbidities as these are targets for prehabilitation programs [8]. Since 2012, as part of a National Patient Safety Program in the Netherlands, all patients over 70 years should be subjected to a short evaluation of four domains: undernutrition, physical impairment, delirium risk and fall risk. This short screening method is easy and less time consuming than a full geriatric assessment, but provides some important prognostic information about outcome and morbidity [33]. When patients seem to be at risk for frailty it is important to perform a complete geriatric assessment in these patients. The most eligible tool to identify frail from fit patients in the geriatric oncological group appears to be the Comprehensive Geriatric Assessment (CGA) [32]. CGA uses a more multidimensional approach than ASA score does, assessing functional, psychosocial and physical health status, polypharmacy and cognition. Although time consuming, CGA has been shown to be a useful predictor for postoperative complications in senior patients [32]. In our institution all patients are seen by the surgeon and anesthesiologist to asses peri-operative risk and to shortly evaluate the four geriatric domains. If increased risk is considered, patients are referred for a full geriatric assessment. If indicated, in some of these patients, prehabilitation programs were initiated. Nevertheless, all senior patients were advised to increase protein intake and to try to double their standard physical exercise in the waiting period for surgery.

Intense prehabilitation programs as standard care for all CRC patients have not shown to be of value yet, although in selected patients enhancing preoperative condition with prehabilitation programs could be useful in decreasing postoperative complications and improved recovery [34,35]. Studies performed in frail patients undergoing intra-abdominal surgery showed that prehabilitation decreases postoperative complications with $40-50 \%$. Other promising results were achieved in orthopedic and cardiac surgery patients [13,36-38]. It is believed that the frailest patients benefit most from these programs, but they are often excluded from studies and therefore the effect of these programs on older and frail CRC patients is still uncertain [12]. In addition, as our results show major improvement in postoperative mortality and outcome in the current era, and we did not implement prehabilitation programs in all patients, the effect of prehabilitation for the majority of the older population is probably small. The challenge is to find which patient in daily practice could be planned for surgery and which will benefit most from a prehabilitation program. Hopefully future studies focusing on this topic will provide more insight in the selection of patients.

The strength of this study lies in the availability of many clinical variables in a large population of patients with a low prevalence of missing values. Limitations of this study are based on its retrospective character. The report on minor complications could be underestimated due to a lack of documentation. However, we believe that the underestimation of complications was kept to a minimum by accurate studying of medical records, contact with referral hospitals and general practitioners and direct contact with patients by telephone. Assessment and screening for frailty has been implemented gradually since 2012 as it was part of a national health program. If frailty was suspected, the patients were referred for geriatric assessment. Therefore, only a few patients were assessed with a CGA and subjected to a prehabilitation program, thus we do not know the impact of prehabilitation on postoperative outcomes as this was not standard care. Over the years, we found slightly lower incidences of $\geq 3$ comorbidities in senior patients. We believe this is due to a difference in documentation of comorbidities, rather than that outcomes have been influenced by only selecting the best patients for treatment.

As most of our rectal cancer patients are referred, there could also be an effect of selection bias for this specific patient group. Therefore, we believe that all patients with locally advanced rectal cancer cases should be discussed in a regional multidisciplinary team meeting (MDT) or should be referred to a tertiary center before declining curative treatment.

This study shows that relative survival in the first year for senior patients undergoing CRC surgery has improved greatly over the past years. Their relative survival is even equal to that of younger patients. Therefore, all senior patients regardless of age should be adequately staged and discussed in a MDT meeting and when in doubt of frailty, patients should be referred to a geriatrician prior to declining treatment. We believe that the outcomes of this study are promising and senior patients should not be withheld curative treatment based on age or comorbidities alone.

\section{Conclusion}

Postoperative morbidity in senior CRC patients has decreased and survival has improved over the latest years. Currently, 30- and 90-day mortality and relative 1 -year survival are almost equal for older and younger CRC patients. All senior CRC patients should be adequately staged and screened before any treatment plan is determined. Clinicians should not withheld senior patients from curative treatment based on age or comorbidities alone.

\section{Conflict of interest statement}

None.

\section{Funding}

None.

\section{Appendix A. Supplementary data}

Supplementary data related to this article can be found at https://doi.org/10.1016/j.ejso.2019.06.017.

\section{References}

[1] Winther SB, Baatrup G, Pfeiffer P, Qvortrup C. Trends in colorectal cancer in the elderly in Denmark, 1980-2012. Acta Oncol 2014;55(1):29-39.

[2] Papamichael D, Audisio RA, Glimelius B, de Gramont A, Glynne-Jones R, Haller D, et al. Treatment of colorectal cancer in older patients: international society of geriatric oncology (SIOG) consensus recommendations 2013. Ann Oncol 2015;26(463):476.

[3] Rutten HJT, den Dulk M, Lemmens VE, van de Velde CJH, Marijnen CAM. Controversies of total mesorectal excision for rectal cancer in elderly patients. Lancet Oncol 2008;9:494-501.

[4] Shahir MA, Lemmens VEPP, van de Poll-Franse LV, Voogd AC, Martijn H, 
Janssen-Heijnen MLG. Elderly patients with rectal cancer have a higher risk of treatment-related complications and a poorer prognosis than younger patients: a population-based study. Eur J Cancer 2006;42(17):3015-21.

[5] Al-Abed Y, Parker M, Arulampalam T, Tutton M. Survival following rectal cancer surgery: does the age matter? Acta Chir Belg 2018:1-7.

[6] Claassen YHM, Vermeer NCA, Iversen LH, van Eycken E, Guren MG, Mroczkowski P, et al. Treatment and survival of rectal cancer patients over the age of 80 Years: a EURECCA international comparison. Br J Canc 2018;119: $517-22$.

[7] Yamano T, Yamauchi S, Kimura K, Babaya A, Hamanaka M, Kobayashi M, et al. Influence of age and comorbidity on prognosis and application of adjuvant chemotherapy in elderly Japanese patients with colorectal cancer: a retrospective multicentre study. Eur J Cancer 2017;81:90-101.

[8] Montroni I, Ugolini G, Saur NM, Spinelli A, Rostoft S, Millan M, et al. Personalized management of elderly patients with rectal cancer: expert recommendations of the european society of surgical oncology, european society of coloproctology, international society of geriatric oncology, and American college of surgeons commission on cancer. Eur J Surg Oncol 2018;44: 1685-702.

[9] Jung B, Pahlman L, Johansson R, Nilsson E. Rectal cancer treatment and outcome in the elderly: an audit based on the Swedish rectal cancer registry 1995-2004. BMC Canc 2009;9(68).

[10] Samuelsson KS, Egenvall M, Klarin I, Lökk J, Gunnarsson U. Preoperative geriatric assessment and follow-up of patients older than 75 Years undergoing elective surgery for suspected colorectal cancer. J Geriatr Oncol 2019 Feb 7. https://doi.org/10.1016/j.jgo.2019.01.020.

[11] Dekker JW, van den Broek CB, Bastiaannet E, van de Geest LG, Tollenaar RA, Liefers GJ. Importance of the first postoperative year in the prognosis of elderly colorectal cancer patients. Ann Surg Oncol 2011;18(6):1533-9.

[12] Bruns ER, van den Heuvel B, Buskens CJ, van Duijvendijk P, Festen S, Wassenaar EB, et al. The effects of physical prehabilitation in elderly patients undergoing colorectal surgery: a systematic review. Colorectal Dis 2016;18(8):267-77.

[13] Moran J, Guinan E, McCormick P, Larkin J, Mockler D, Hussey J, et al. The ability of prehabilitation to influence postoperative outcome after intraabdominal operation: a systematic review and meta-analysis. Surgery 2016;160(5):1189-201.

[14] Berkel AEM, Bongers BC, van Kamp MS, Kotte H, Weltevreden P, de Jongh FHC, et al. The effects of prehabilitation versus usual care to reduce postoperative complications in high-risk patients with colorectal cancer or dysplasia scheduled for elective colorectal resection: study protocol of a randomized controlled trial. BMC Gastroenterol 2018;18(1):29.

[15] Dutch national Guidelines colorectal cancer. 2014. 11-2-2019. Ref Type: Report.

[16] Dindo D, Demartines N, Clavien PA. Classifications of surgical classifications. Ann Surg 2004;240(2):205-13.

[17] Clavien PA, Barkun J, de Oliveira ML, Vauthey JN, Dindo D, Schulick RD, et al. The clavien-dindo classification of surgical complications: five-year experience. Ann Surg 2009;250(2):187-96.

[18] Weerink LBM, Gant CM, van Leeuwen BL, de Bock GH, Kouwenhoven EA, Faneyte IF. Long-term survival in octogenarians after surgical treatment for colorectal cancer: prevention of postoperative complications is key. Ann Surg Oncol 2018;25(13):3874-82.

[19] Duraes LC, Stocchi L, Steele SR, Kalady MF, Church JM, Gorgun E, et al. The relationship between clavien-dindo morbidity classification and oncologic outcomes after colorectal cancer resection. Ann Surg Oncol 2018;25(1): 188-96.

[20] Aoyama T, Oba K, Honda M, Sadahiro S, Hamada C, Mayanagi S, et al. Impact of postoperative complications on the colorectal cancer survival and recurrence: analyses of pooled individual patients' data from three large phase III randomized trials. Cancer Med 2017;6(7):1573-80.

[21] Al-Refaie WB, Parsons HM, Habermann EB, Kwaan M, Spencer MP, Henderson WG, et al. Operative outcomes beyond 30-day mortality : colorectal cancer surgery in oldest old. Ann Surg 2011;253(5):947-52.

[22] Dinnewitzer A, Nawara C, Augschöll C, Neureiter D, Hitzl W, Öfner D, et al. The impact of advanced age on short- and long-term results after surgery for colorectal cancer. Eur Surg 2015;47(6):331-6.

[23] Yen C, Simillis C, Choudhry M, Mils S, Warren O, Tekkis PP, et al. A comparative study of short-term outcomes of colorectal cancer surgery in the elderly population. Acta Chir Belg 2017;117(5):303-7.

[24] Kornmann VNN, van Vugt JLA, Smits AB, van Ramshorst B, Boerma D. The first year after colorectal surgery in the elderly. Ann Coloproctology 2017;33(4): 134-8.

[25] Banysh M, Akkaya T, Gurenko P, Papadakis M, Heuer T, Kasim E, et al. Surgery for colorectal cancer in elderly patients: is there such a thing as being too old? Il G Chir 2018;39(6):355-62.

[26] Breugom AJ, Bastiaannet E, Dekker JWT, Wouters MWJM, van de Velde CJH, Liefers GJ. Decrease in 30-day and one-year mortality over time in patients aged $=75$ Years with stage I-III colon cancer: a population-based study. Eur J Surg Oncol 2018;44(12):1889-93.

[27] Claassen YHM, Bastiaannet E, van Eycken E, van Damme N, Martling A, Johansson R, et al. Time trends of short-term mortality for octogenarians undergoing a colorectal resection in North Europe. Eur J Surg Oncol. 2019;45(8):1396-402. https://doi.org/10.1016/j.ejso.2019.03.041.

[28] Jafari MD, Jafari F, Halabi WJ, Nguyen VQ Pigazzi A, Carmichael JC, et al. Colorectal cancer resections in the aging US population: a trend toward decreasing rates and improved outcomes. JAMA Surgery 2014;149(6): 557-64.

[29] Ouakrim DA, Pizot C, Boniol M, Malvezzi M, Boniol M, Negri E, et al. Trends in colorectal cancer mortality in europe: retrospective analysis of the WHO mortality database. Br Med J 2015;351:h4970.

[30] Fagard K, Leonard S, Deschodt M, Devriendt E, Wolthuis A, Prenen H, et al. The impact of frailty on postoperative outcomes in individuals aged 65 and over undergoing elective surgery for colorectal cancer: a systematic review. J Geriatr Oncol 2016;7(6):479-91.

[31] Lin HS, Watts JN, Peel NM, Hubbard RE. Frailty and post-operative outcomes in older surgical patients: a systematic review. BMC Geriatr 2016;16(157).

[32] Orsini RG, Rostoft S, Rutten HJ. Rectal cancer treatment in elderly. In: Longo WE, Reddy V, Audisio RA, editors. Modern management of cancer of the rectum; 2015. p. 385-403.

[33] Souwer ETD, Hultink D, Bastiaannet E, Hamaker ME, Schiphorst A, Pronk A et al. The prognostic value of a geriatric risk score for older patients with colorectal cancer. Ann Surg Oncol 2019;26(1):71-8.

[34] Partridge JSL, Harari D, Dhesi JK. Frailty in the older surgical patient: a review. Age Ageing 2012;41(2):142-7.

[35] Mayo NE, Feldman L, Scott S, Zavorsky G, Kim DJ, Charlebois P, et al. Impact of preoperative change in physical function on postoperative recovery: argument supporting prehabilitation for colorectal surgery. Surgery 2011;150(3): 505-14.

[36] Barberan-Garcia A, Ubré M, Roca J, Lacy AM, Burgos F, Risco R, et al. Personalised prehabilitation in high-risk patients undergoing elective major abdominal surgery: a randomized blinded controlled trial. Ann Surg 2018;267(1):50-6.

[37] Santa Mina D, Clarke H, Ritvo P, Leung YW, Matthew AG, Katz J, et al. Effect of total-body prehabilitation on postoperative outcomes: a systematic review and meta-analysis. Physiotherapy 2014;100(3):196-207.

[38] Mans CM, Reeve JC, Gasparini CA, Elkins MR. Postoperative outcomes following preoperative inspiratory muscle training in patients undergoing open cardiothoracic or upper abdominal surgery: protocol for a systematic review. Syst Rev 2012;1(63). 